\section{Evaluation of the efficacy of a training course in food safety addressed to food charity volunteers}

\author{
Daniela Manila Bianchi, ${ }^{1}$ Ilaria Giorgi, ${ }^{2}$ \\ Fabio Zuccon, ${ }^{1}$ Donatella De Somma, ${ }^{2}$ \\ Valeria D'Errico, ${ }^{2}$ Walter Martelli, ${ }^{2}$ \\ Adolfo Muzzani, ${ }^{3}$ Vilma Soncin, ${ }^{3}$ \\ Salvatore Collarino, ${ }^{3}$ Daniela Adriano, ${ }^{1}$ \\ Lucia Decastelli ${ }^{1}$
}

${ }^{1}$ Food Control and Production Hygiene Unit and ${ }^{2}$ Biostatistics Epidemiology and Risk Analysis Unit, The Veterinary Medical Research Institute for Piedmont, Liguria and the Aosta Valley, Turin; ${ }^{3}$ Banco Alimentare Piemonte Onlus, Moncalieri, Italy

\begin{abstract}
In Italy, the Banco Alimentare Onlus manages a network of 8,000 charitable organizations that distribute 67,000 tons of foodstuffs to 1.6 million needy persons. To provide their volunteers with the required food safety knowledge, the Banco Alimentare del Piemonte Onlus commissioned the Istituto Zooprofilattico Sperimentale del Piemonte, Liguria e Valle d'Aosta to hold training courses in food safety. Before and after each session, the participants completed a questionnaire to evaluate their knowledge on the topic of food safety. The responses were entered in a dedicated database and analyzed using STATA ver. 15.1. Comparison of the scores for each participant before and after training revealed a considerable discordance [ICC $0.06,95 \%$ confidence interval (CI) 0.00 0.18]. Analysis of the post-training questionnaires showed that the number of questions left unanswered decreased and the number of correct answers increased. The difference between the percentage of correct and incorrect responses before and after the training course was statistically significant $(\mathrm{P}<0.001)$. Comparison of responses to the pre- and post-training questionnaires provided the data for statistical evaluation of the efficacy of the training course.
\end{abstract}

\section{Introduction}

Every year, about 173 kilograms of food per capita are wasted in Europe. Nearly half of the foodstuff for human consumption that is lost or wasted occurs at the end of the food chain: distribution and private consumption (Katasarova, 2017). Wasting food is both an ethical and an economic problem with a huge environmental impact. The data presented at a conference held by the Food and Agricultural Organization of the United Nations in 2015 paint a clear picture - if garbage and food wastage were a nation, it would rank third for the volume of greenhouse gas emissions generated (FAO, 2015). It is estimated that 5 million tons of unsold but still consumable food are discarded every year in Italy (CREA, 2019). Food recovery and distribution to the needy is largely managed by charities or other nonprofit organizations. The legal underpinnings of food donation have recently been streamlined with the enactment of Law 166/2016 (Gazzetta Ufficiale Italiana, 2016) that regulates the distribution of foodstuffs for social solidarity and to curb food wastage. The law allows the donation of food products after the date of minimum durability (DMD), or colloquially "best before" date, if the product has been stored appropriately and the package is unopened and intact. The responsibility falls to either operators of the retail food chain, for example, supermarket warehouse workers, or to food charity volunteers who collect, store, and redistribute the food (European Parliament, 2002). While professional food workers are familiar with good hygiene and food conservation practices, the same cannot be assumed for food charity volunteers who may not be aware of the important role they play in maintaining food safety standards.

In Italy, the Banco Alimentare Onlus [non-profit food bank] manages a network of 8,000 charitable organizations that distribute 67,000 tons of foodstuffs to 1.6 million needy persons (Food Bank, 2017a). In 2017, the Piedmont chapter alone distributed to over 112,000 persons about 6,800 tons through 600 charities operating under contract with the food bank (Food Bank, 2017b). Under the provisions of Law $166 / 2016$, food charity volunteers must have good knowledge of the principles of hygiene and food safety, appropriate storage methods, and be able to distinguish between "use by" date and "best before" date.

To provide their volunteers with the required food safety knowledge, the Banco Alimentare del Piemonte Onlus commissioned our unit, the Food Safety and Hygiene of Productions of the Istituto Zooprofilattico Sperimentale del Piemonte, Liguria e Valle d'Aosta to hold training courses in food safety. The present article reports the results of efficacy evaluation of the training courses. The data were obtained from questionnaires administered to course participants before and after the course.
Correspondence: Daniela Manila Bianchi, Via Bologna 148, 10154, Torino Italy.

Tel.: +39.011.2686465.

E-mail: manila.bianchi@izsto.it

Key words: food safety, food hygiene, training, food waste.

Acknowledgments: The authors are grateful to Compagnia di Sanpaolo who partially funded this project.

Contributions: The authors contributed equally.

Conflict of interest: The authors declare no potential conflict of interest.

Funding: None.

Received for publication: 30 May 2019.

Revision received: 18 September 2019.

Accepted for publication: 16 October 2019.

This work is licensed under a Creative Commons Attribution-NonCommercial 4.0 International License (CC BY-NC 4.0).

(C) Copyright: the Author(s), 2019

Licensee PAGEPress, Italy

Italian Journal of Food Safety 2019; 8:8316

doi:10.4081/ijfs.2019.8316

\section{Materials and Methods}

Between March and June 2018, our unit held food safety training courses for about 450 food charity volunteers. The objective of the one-day course was to provide the volunteers with essential notions of food safety, including good hygiene and food handling practices compliant with high safety standards for the distribution of meals. The course was held in seven cities throughout the region of Piedmont (Moncalieri, Biella, Asti, Vercelli, Alessandria, Fossano, and Novara). Sessions lasted $3.5 \mathrm{~h}$. Before and after each session, the participants completed a questionnaire to evaluate their knowledge on the topic of food safety. The two-part questionnaire included 11 questions (Table 1). The first part (questions 1-5) dealt with European and Italian norms regulating food safety and food distribution; the second part (questions 6-11) asked about operating practices that ensure food safety and hygiene, as well as the management of food distribution.

The responses were entered in a dedicated database and analyzed using STATA ver. 15.1 (Stata, 2017). The data were tested for normal distribution. Concordance between the responses given before and those given after the training session was evaluated using the Wilcoxon 
test and the intraclass correlation coefficient (ICC). The binominal test was performed to compare the percentage of correct responses to incorrect responses and to blank responses. The test was also used to evaluate the difference in the percentage of course participants before and after training who had left questions unanswered.

For each multiple-choice question one or more responses were correct. To evaluate and calculate the total score, 1 point was given if all the responses to the question were correct; 0.5 point was given if 1 out of 2 responses was correct; 0.5 point if one or more responses were incorrect but the answer contained also correct responses; 0 if the question was left blank; -0.25 if the response was incorrect. The passing grade was a total score of 3.5 ; the maximum score was 6.

\section{Results}

In all, 204 questionnaires were returned. Analysis of the pre-training questionnaires showed that $37 \%$ of the questionnaires contained correct responses to all 11 questions, $23 \%$ contained some correct responses, $27 \%$ contained incorrect responses to all 11 items, and 13\% had blanks. The breakdown for the post-training questionnaires was: $45 \%$ all correct responses, $37 \%$ some correct responses, $14 \%$ incorrect responses, and 3\% had blanks. We also took a closer look at the responses to questions 6 through 11 to determine pre- and post-training differences in acquisition of knowledge about correct food safety practices and food distribution. Analysis of the pre-training questionnaires showed that while only $8.8 \%$ of the course participants scored at least 3.5 , some $43.6 \%$ achieved a passing grade after having received training.

The mean score was 1,91 before and 3,27 after training.

Some $79.9 \%$ of participants scored higher on the post-training questionnaire, $9.8 \%$ had the same score on both questionnaires, and $10.3 \%$ had a lower score; this difference was significant on the Wilcoxon test $(\mathrm{P}<0.001)$.

Comparison of the scores for each participant before and after training revealed a considerable discordance (ICC 0.06, 95\% CI 0.00-0.18). The mean number of correct responses for each participant was 1.4 before and 2.7 after training. Figure 1 presents the percentages of all correct, partially correct, incorrect, and blank responses before and after the training course. The difference between the percentage of correct and incorrect responses before and after the training course was statistically significant $(\mathrm{P}<0.001)$.

Figure 1 presents the number of correct responses for each questionnaire: $23 \%$ of the participants did not respond correctly to any of the questions before training, while only $3 \%$ did not respond correctly to all 6 questions in the second part of the questionnaire after training. The number of questionnaires with 3 or more completely correct responses was $15 \%$ before and $58 \%$ after training (Figure 2). Figure 3 reports the number of blank responses for each questionnaire: $8 \%$ of participants left their questionnaire blank before training, while all participants answered at least 1 question after training. The number of questionnaires completed was $72 \%$ before and $90 \%$ after training. The difference was statistically significant $(\mathrm{P}<0.001)$.

The questions that were most often left blank before training were number 7 (DMD) and number 11 (whether food past the DMD

Table 1. Questionnaire administered before and at the end of the training session. Correct answers are underlined.

\section{PART 1}

1. The Food Hygiene Package is:

a) a set of laws that regulate the trade in food products.

b) the legal basis for norms regulating food safety and hygiene.

c) The package containing foods for needy

2. Law 155/2003 "The Good Samaritan":

a) provides that non-profit charitable organizations are equal to the final consumer.

b) provides that the donor is protected against liabilities resulting from the donation of food products.

c) refers to people who help the needy

3. Law 166/2016:

a) regulates provisions regarding the donation and distribution of food products and pharmaceuticals for charitable purposes and to reduce wastage.

b) is known also as the "Gadda Law".

c) sanctions personnel working with the needy

4. Regulation $\mathrm{EC} / 178 / 2002$ :

a) regulates the production of food derivatives.

b) is a piece of key food safety legislation; it was the first to reform EC regulations on food hygiene.

c) a set of laws that regulate free trade in food products.

5. Regulation EC/882/2004:

a) is a piece of key food safety legislation.

b) Is part of the Food Hygiene Package regulating official controls.

c) is addressed to food business operators as concerns the HACCP system.

\section{PART 2}

6. Expiration is indicated on the label as:

a) "use by" date.

b) "best before" date.

c) keep refrigerated.

d) store in a cool, dry place.

7. DMD is:

a) the expiration date

b) the date until which a food product should be consumed.

c) the date until which a food product retains its specific properties.

d) the date within which a food product is safe for the consumer.

8. The hazards to health of a food product:

a) can be biological, physical, chemical hazards.

b) are high, medium, low.

c) need to be controlled along the entire food chain.

d) are eliminated through coking.

9. You should wash your hands after

a) using the bathroom.

b) eating or smoking.

c) cleaned rooms and equipment.

d) using the telephone.

10. Can a food product be safely consumed after the "use by" date?

a) Yes, always.

b) No, never.

c) Yes, if it has been appropriately stored.

d) Yes, if there are no macroscopic changes.

11. Can a food product be safely consumed after the DMD?

a) Yes, always.

b) No, never.

c) Yes, if it has been appropriately stored.

d) Yes, if there are no macroscopic changes. 
can still be safely consumed) and both were left unanswered by $14.7 \%$ of participants, while after training $1.5 \%$ did not answer question 7 and $3.4 \%$ did not answer question 11. The largest pre- versus post-training gain $(+41.7 \%)$ in correct answers was noted for question number 9 on personal hygiene, whereas the smallest gain $(+8 \%)$ was observed for question 8 on hazards to human health.

\section{Discussion}

The food safety training sessions were carried out regularly and to the satisfaction of all participants. The duration of the sessions and the amount of time devoted to the various topics were sufficient for achieving the learning goals set for the course. Data for the efficiency evaluation were obtained from the pre- and posttraining questionnaires. A more detailed statistical analysis of questions 6 to 11 was performed as the topics of this part of the questionnaire present the more significant strategies where volunteers can act in order to achieve high safety level of food. We also took a closer look at the responses to questions 6 through 11 to determine pre- and post-training differences in acquisition of knowledge about correct food safety practices and food distribution

In general, the course provided the participants with knowledge of food safety they did not possess before taking the course: analysis of the post-training questionnaires showed that the number of questions left unanswered decreased and the number of correct answers increased. More than one correct answer was possible on some of the multiple-choice questions. This was done to determine whether at the end of the course the participants had acquired a deeper understanding that would allow them to answer more precisely. For example, all 4 answers to question 9 are correct: only 77 out of 204 answered correctly on the pretraining questionnaire, but $162 \mathrm{did}$ so at the end of the course. In detail, most participants gave "a" as the correct answer on the pretraining questionnaire. Indeed, handwashing after using the bathroom is part of general real-world knowledge. Starting from this basic notion, the course added new knowledge relevant for food handlers who must maintain a high level of personal hygiene. Accordingly, the question required answering "b" through "d" besides "a".

Similarly, there were two correct answers to question 8: "a" referred to physical, chemical, and microbiological hazards; this response was correctly given on the pre- and post-training questionnaires

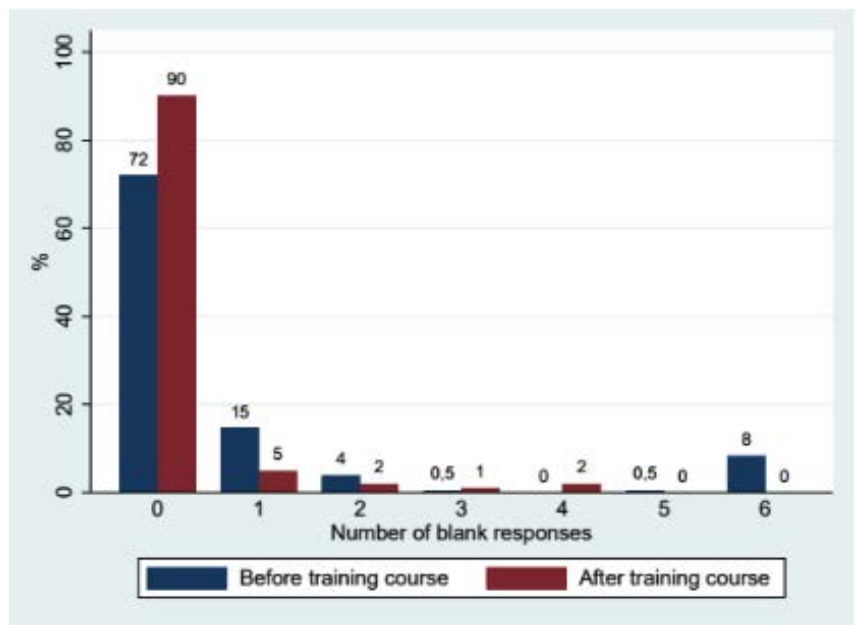

Figure 1. Percentage of correct, partially correct, incorrect, and blank responses before and after training.

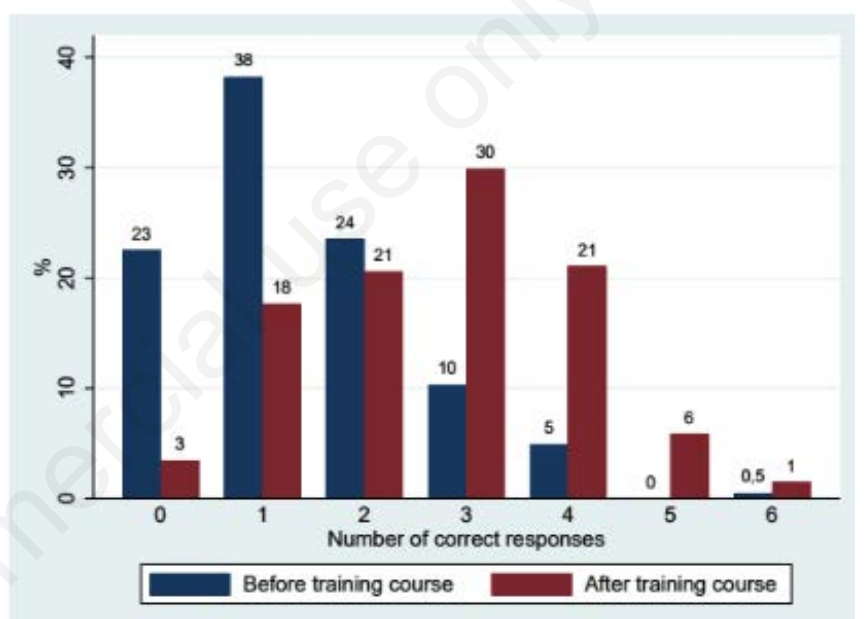

Figure 2. Comparison of correct responses before and after the training: on the $x$ axis there is the absolute number of correct answers (from a minimum of 0 to a maximum of 6); on $y$ axis there is the proportion of correct responses.

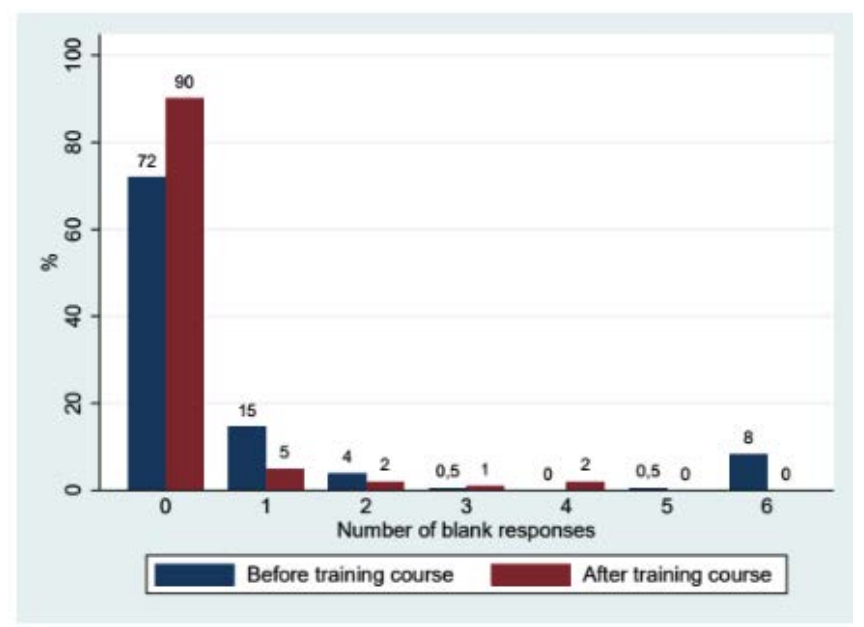

Figure 3. Comparison of the responses left blank before and after the training; on the $x$ axis there is the absolute number of responses left blank and on the $y$ axis the proportion of the responses left blank. 
(121/175 and 161/195, respectively). Response "c" referred to the possibility that hazards can be kept under control along the entire food chain; however, few participants gave this answer perhaps because it is difficult for food volunteers to imagine that their actions can have an effect on packaged food that they do not handle directly. Comparison of the pre- and post-training results showed a $4.4 \%$ increase in correct response to this question.

An intriguing finding was the responses to questions 6 and 7 on the definition of "use by" and "best before" dates, respectively. The Food Waste and Date Marking survey conducted by the European Commission was a telephone survey involving 26,601 participants in 28 Member States. It revealed that less than half of the interviewees knew the difference between "best before" and "use by". Analysis of the pre-training questionnaires showed that the course participants could not distinguish between the two: 41 out of 183 responded incorrectly that a product's expiry date is given as "best before" on the food label (answer "b") and 65 out of 183 responded that both "best before" and "use by" (answers "a" and "b") are correct. Having a clear understanding of the difference between the two is essential for food charity volunteers. Enactment of Law 106/2016, the so-called Gadda Law, made it possible that food products can be distributed after the DMD but not after the "use by" date. Based on questionnaire responses, and answers to questions 10 and
11 on the consumption of food products after expiration of their shelf life in particular, the training course provided participants with the knowledge that a food product can still be consumed after the DMD.

\section{Conclusions}

Participants attending the course were able to show that they had improved their knowledge of the training topics and met the objectives the organizers had set for the course. Having a clear understanding of the difference between "best before" and "use by" dates allows for application of Law 106/2016. The food charity volunteers would do well to share this knowledge with the people they serve, so that they realize that a food item can still be safely consumed after the DMD. Comparison of responses to the pre- and post-training questionnaires provided the data for statistical evaluation of the efficacy of the training course.

\section{References}

CREA, 2019. Rapporto dell'Osservatorio sulle eccedenze, sui recuperi e sugli sprechi alimentari Ricognizione delle misure in Italia e proposte di sviluppo. A cura di Ministero delle politiche agricole, agroalimentari, forestali e del turismo e Crea-Consiglio per la ricerca in agricoltura e l'analisi dell'economia agraria. ISBN 978-88-3385-006-1

European Parliament, 2002. Regulation (EC) No 178/2002 of 28 January 2002 laying down the general principles and requirements of food law, establishing the European Food Safety Authority and laying down procedures in matters of food safety. Official Journal of European Union, Vol. 31 pp. 1-24

FAO, 2015. Available from: http://www.fao.org/3/a-bb144e.pdf

Food Bank, 2017a. Fondazione Banco Alimentare Onlus. Available from: www.bancoalimentare.it

Food Bank, 2017b. Banco Alimentare Piemonte Onlus, Relazione attività 2017. Available from: www.bancoalimentarepiemonte.it/it/torino

Gazzetta Ufficiale Italiana, 2016. Legge 19 agosto 2016 n. 166: Disposizioni concernenti la donazione e la distribuzione di prodotti alimentari e farmaceutici a fini di solidarieta' sociale e per la limitazione degli sprechi. In: Gazzetta Ufficiale, 202, 30/08/2016.

Katsarova I, 2017. Initiative on resource efficiency: reducing food waste, improving food safety. 2016/2223(INI). Available from: http://www.europarl. europa.eu/RegData /etudes/ATAG/2017/603909/EPRS_AT A(2017)603909_IT.pdf

StataCorp, 2017. Stata Statistical Software: Release 15. College Station, TX: StataCorp LP 